\title{
Establishing New Diffuse Solar Radiation Equations for Antalya, Turkey
}

\author{
${ }^{1}$ Ceyda Aksoy Tırmıkçı and ${ }^{* 2}$ Cenk Yavuz \\ ${ }^{1,2}$ Faculty of Engineering, Department of Electrical and Electronics Engineering Sakarya University, Turkey
}

\begin{abstract}
In this paper new diffuse solar radiation equations were established for Antalya, Turkey. For this purpose current equations from the literature which were functions of the clearness index and/or the sunshine fraction were examined. 9 equations were selected to determine the regression constants of the new equations. In conclusion the best equation among the new equations was introduced on the basis of different statistical indicators.
\end{abstract}

Key words: Diffuse solar radiation, regression constant, clearness index, sunshine fraction

\section{Introduction}

Turkey has become prominent as a fast growing country in recent years. Sustainability of this growth is doubtful since the country is heavily dependent on imported fossil fuels for meeting its rising energy demands [1]. The key to break this dependency is to increase the share of renewable energy sources of the country in power generation.

Solar energy potential of Turkey was recorded to be enormous with the annual average solar radiation of $3.6 \mathrm{~kW} \mathrm{~h} / \mathrm{m}^{2}$ day and the total yearly solar radiation period of $2640 \mathrm{~h} \mathrm{[2].} \mathrm{Antalya}$ makes the most significant contribution to this enormous potential as one of the sunniest cities of the country with the annual average global solar radiation of $3.93 \mathrm{kWh} / \mathrm{m}^{2}$ and the annual average sunshine hours of $8.25 \mathrm{~h} \mathrm{[3]}$.

The efficiency of solar energy systems is directly related to the total solar radiation received on the PV module surface. Therefore it is important to consider this parameter when determining the inclination angle of PV modules [4]. Today the global solar radiation is easily measured almost all over the world. However the diffuse solar radiation which is required to calculate the total solar radiation is available for very few locations.

In this paper the monthly average diffuse solar radiation estimation was carried out for Antalya city, Turkey. For this purpose new diffuse solar radiation equations were developed using the current selected equations from the literature. In this regard the clearness index and sunshine fraction were used to define the diffuse fraction. In conclusion the best equation for the city was established on the basis of different statistical indicators.

*Corresponding author: Address: Faculty of Engineering, Department of Electrical and Electronics Engineering Sakarya University, 54187, Sakarya TURKEY. E-mail address: caksoy@sakarya.edu.tr, Phone: +902642955632 


\section{Materials and Method}

In this paper new diffuse solar radiation equations were developed using the current equations which correlated the diffuse fraction with the clearness index and/or sunshine fraction. The current equations were evaluated in three groups (Table 1). Here the clearness index is the global solar radiation $(H)$ divided by the extraterrestrial solar radiation $\left(H_{0}\right)$, the sunshine fraction is sunshine hours $(S)$ divided by the maximum sunshine hours $\left(S_{0}\right)$ and the diffuse fraction is the diffuse solar radiation $\left(H_{d}\right)$ divided by the global solar radiation $(H)$.

Table 1. Current diffuse solar radiation equations selected from the literature

Group 1: the diffuse fraction $\left(H_{d} / H\right)$ correlated with the clearness index $\left(H / H_{0}\right)$

1. $\frac{H_{d}}{H}=1.00-1.13 \times\left(\frac{H}{H_{0}}\right)$

2. $\frac{H_{d}}{H}=1.1244-1.5582 \times\left(\frac{H}{H_{0}}\right)+0.3635\left(\frac{H}{H_{0}}\right)^{2}$

3. $\frac{H_{d}}{H}=1.027-1.6582 \times\left(\frac{H}{H_{0}}\right)+1.1018 \times\left(\frac{H}{H_{0}}\right)^{2}-0.4019 \times\left(\frac{H}{H_{0}}\right)^{3}$

Group 2: the diffuse fraction $\left(H_{d} / H\right)$ correlated with the sunshine fraction $\left(S / S_{0}\right)$

4. $\frac{H_{d}}{H}=0.791-0.635 \times\left(\frac{S}{S_{0}}\right)$

5. $\frac{H_{d}}{H}=0.7434-0.8203 \times\left(\frac{S}{S_{0}}\right)+0.2454 \times\left(\frac{S}{S_{0}}\right)^{2}$

6. $\frac{H_{d}}{H}=0.5562+0.1536 \times\left(\frac{S}{S_{0}}\right)-1.2027 \times\left(\frac{S}{S_{0}}\right)^{2}+0.7122 \times\left(\frac{S}{S_{0}}\right)^{3}$

Group 3: the diffuse fraction $\left(H_{d} / H\right)$ correlated with the clearness index $\left(H / H_{0}\right)$ and the sunshine fraction $\left(S / S_{0}\right)$

7. $\frac{H_{d}}{H}=1.00-0.858 \times\left(\frac{H}{H_{0}}\right)-0.235 \times\left(\frac{S}{S_{0}}\right)$

8. $\frac{H_{d}}{H}=0.945-0.675 \times\left(\frac{H}{H_{0}}\right)-0.166 \times\left(\frac{H}{H_{0}}\right)^{2}-0.173 \times\left(\frac{S}{S_{0}}\right)-0.079 \times\left(\frac{S}{S_{0}}\right)^{2}$ 
Table 1. (cont.)

$\frac{H_{d}}{H}=0.9593-0.8713 \times\left(\frac{H}{H_{0}}\right)+0.29191 \times\left(\frac{H}{H_{0}}\right)^{2}-0.0979 \times\left(\frac{H}{H_{0}}\right)^{3}$
$-0.28419 \times\left(\frac{S}{S_{0}}\right)+0.02653 \times\left(\frac{S}{S_{0}}\right)^{2}-0.02083 \times\left(\frac{S}{S_{0}}\right)^{3}$

The global solar radiation $(H)$ and sunshine hours $(S)$ were obtained from the solar energy potential atlas by Turkey Renewable Energy Head Office. The extraterrestrial solar radiation $\left(H_{0}\right)$ and maximum possible sunshine hours $\left(S_{0}\right)$ were calculated from mathematical expressions below [1315]:

$H_{0}=\frac{24 \times 3600}{\pi} \times G_{0}$

$S_{0}=\frac{2}{15} \times w_{S}$

where $G_{0}$ and $w_{s}$ are the corrected solar constant and the sunrise hour angle for horizontal surface respectively.

Measured monthly average data of $H$ and $S$ and calculated monthly average data of $H_{0}$ and $S_{0}$ were used in the equations presented in Table 1 to predict the monthly average diffuse solar radiation. Then the regression coefficients for Equations (12)-(14) were determined by using the predicted data of diffuse solar radiation.

$$
\begin{aligned}
& \frac{H_{d}}{H}=c_{0}+c_{1} \times\left(\frac{H}{H_{0}}\right)+c_{2} \times\left(\frac{H}{H_{0}}\right)^{2}+c_{3} \times\left(\frac{H}{H_{0}}\right)^{3} \\
& \frac{H_{d}}{H}=c_{0}+c_{1} \times\left(\frac{S}{S_{0}}\right)+c_{2} \times\left(\frac{S}{S_{0}}\right)^{2}+c_{3} \times\left(\frac{S}{S_{0}}\right)^{3} \\
& \frac{H_{d}}{H}=c_{0}+c_{1} \times\left(\frac{H}{H_{0}}\right)+c_{2} \times\left(\frac{H}{H_{0}}\right)^{2}+c_{3} \times\left(\frac{H}{H_{0}}\right)^{3}+c_{4} \times\left(\frac{S}{S_{0}}\right)+c_{5} \times\left(\frac{S}{S_{0}}\right)^{2}+c_{6} \times\left(\frac{S}{S_{0}}\right)^{3}
\end{aligned}
$$

In conclusion the performance of the new equations were evaluated in terms of the statistical indicators below:

Mean bias error:

$$
M B E=\frac{1}{x_{i=1}^{x}}\left(E V_{i}-M V_{i}\right)
$$


Mean absolute percentage error:

$M A P E=\frac{1}{x} \sum_{i=1}^{x}\left|\frac{E V_{i}-M V_{i}}{M V_{i}}\right|$

Mean absolute bias error:

$M A B E=\frac{1}{x_{i=1}} \sum_{i=1}^{x}\left|E V_{i}-M V i\right|$

Root mean square error:

$$
R M S E=\sqrt{\frac{1}{x_{i=1}^{x}}\left(E V_{i}-M V_{i}\right)^{2}}
$$

Coefficient of determination:

$$
R^{2}=\frac{\sum_{i=1}^{x}\left(E V_{i}-E V a\right) \cdot(M V i-M V a)}{\sqrt{\left[\sum_{i=1}^{x}\left(E V_{i}-E V_{a}\right)^{2}\right]\left[\sum_{i=1}^{x}(M V i-M V a)^{2}\right]}}
$$

t-statistics:

$$
t=\sqrt{\frac{(n-1) M B E^{2}}{R M S E^{2}-M B E^{2}}}
$$

where $E V_{i}$ and $M V_{i}$ express the $i^{\text {th }}$ and $E V_{a}$ and $M V_{a}$ express the average of the estimated and measured values, respectively.

\section{Results}

\subsection{Regression coefficients of the new diffuse solar radiation equations}

Regression coefficients of the new equations obtained from Equation (12)-(14) are as follows:

Table 2. Regression coefficients of the new equations

\begin{tabular}{llllllll}
\hline \multicolumn{2}{l}{ Coefficients from Equation 12} & & & & \\
\hline Equation & $c_{0}$ & $c_{1}$ & $c_{2}$ & $c_{3}$ & $c_{4}$ & $c_{5}$ & $c_{6}$ \\
\hline 15. & 0,932 & -1.045 & 0 & 0 & 0 & 0 & 0 \\
16. & -0.062 & 2.873 & -3.789 & 0 & 0 & 0 & 0 \\
17. & 0.241 & 1.086 & -0.313 & -2.236 & 0 & 0 & 0 \\
\hline \multicolumn{2}{l}{ Coefficients from Equation 13} & $c_{1}$ & $c_{2}$ & $c_{3}$ & $c_{4}$ & $c_{5}$ & $c_{6}$ \\
\hline Equation & $c_{0}$ & $c_{1}$ & & & & & \\
\hline
\end{tabular}


Table 2. (cont.)

\begin{tabular}{|c|c|c|c|c|c|c|c|}
\hline 18. & 0.746 & -0.564 & 0 & 0 & 0 & 0 & 0 \\
\hline 19. & 1.091 & -1.623 & 0.7889 & 0 & 0 & 0 & 0 \\
\hline 20. & -1.339 & 9.922 & -17.123 & 9.079 & 0 & 0 & 0 \\
\hline \multicolumn{8}{|c|}{ Coefficients from Equation 14} \\
\hline Equation & $c_{0}$ & $c_{1}$ & $c_{2}$ & $c_{3}$ & $c_{4}$ & $c_{5}$ & $c_{6}$ \\
\hline 21. & 0.879 & -0.626 & -0.259 & 0 & 0 & 0 & 0 \\
\hline 22. & 0.912 & -0.683 & 0.0660 & -0.316 & 0.038 & 0 & 0 \\
\hline 23. & 0.905 & -0.750 & 0.177 & -0.056 & -0.222 & -0.112 & 0.077 \\
\hline
\end{tabular}

\subsection{Statistical test results of the new diffuse solar radiation equations}

Statistical test results of the new equations with regression coefficients in Table 2 are as follows:

Table 3. Statistical test results of the new equations

\begin{tabular}{|c|c|c|c|c|c|c|}
\hline Equation & $\begin{array}{c}M B E \\
\left(\mathrm{MJ} / \mathrm{m}^{2}\right)\end{array}$ & $\begin{array}{c}M A B E \\
\left(\mathrm{MJ} / \mathrm{m}^{2}\right)\end{array}$ & $\begin{array}{c}M A P E \\
\left(\mathrm{MJ} / \mathrm{m}^{2}\right)\end{array}$ & $\begin{array}{c}R M S E \\
\left(\mathrm{MJ} / \mathrm{m}^{2}\right)\end{array}$ & $R^{2}$ & $t$ \\
\hline 15 & 0.0193 & 0.2133 & 3.6143 & 0.2524 & 0.9873 & 0.2548 \\
\hline 16 & 0.0122 & 0.1318 & 2.4375 & 0.1706 & 0.9942 & 0.2386 \\
\hline 17 & 0.0126 & 0.1314 & 2.4363 & 0.1701 & 0.9943 & 0.2467 \\
\hline 18 & 0.0271 & 0.2322 & 4.0052 & 0.2912 & 0.9850 & 0.3098 \\
\hline 19 & 0.0183 & 0.1448 & 2.8047 & 0.1841 & 0.9937 & 0.3305 \\
\hline 20 & 0.0111 & 0.1467 & 2.5454 & 0.1871 & 0.9929 & 0.1971 \\
\hline 21 & 0.0001 & 0.0048 & 0.0937 & 0.0056 & 1.0000 & 0.0852 \\
\hline 22 & 0.0000 & 0.0008 & 0.0125 & 0.0009 & 1.0000 & 0.0444 \\
\hline 23 & 0.0000 & 0.0000 & 0.0000 & 0.0000 & 1.0000 & 0.0830 \\
\hline
\end{tabular}

Table 3 indicates that Equation 22 gave the best statistical results for the related indicators.

\subsection{Monthly average daily diffuse solar radiation by Equation 22}

Monthly average daily diffuse solar radiation by Equation 22 is as follows:

Table 4. Monthly average daily diffuse solar radiation by Equation 22

\begin{tabular}{ll}
\hline Month & $H_{d}\left[\mathrm{kWh} / \mathrm{m}^{2}\right]$ \\
\hline January & 0.9942 \\
February & 1.1975 \\
\hline
\end{tabular}


Table 4. (cont.)

\begin{tabular}{ll}
\hline March & 1.6432 \\
April & 1.9894 \\
May & 2.1506 \\
June & 2.0511 \\
July & 1.9528 \\
August & 1.7477 \\
September & 1.5183 \\
October & 1.2868 \\
November & 1.0336 \\
December & 0.9192 \\
\hline
\end{tabular}

\section{Discussion}

Table 2 indicates the regression coefficients of the new diffuse solar radiation equations developed for Antalya, Turkey. Table 3 indicates the statistical test results of these new equations by means of $M B E, M A B E, M A P E, R M S E, R^{2}$ and $t$-statistics. According to the table, Equation (21)-(23) where the diffuse fraction $\left(H_{d} / H\right)$ was correlated with the clearness index $\left(H / H_{0}\right)$ and the sunshine fraction $\left(S / S_{0}\right)$ gave the best results among all. Here $t$-statistics values of these equations came to the front as the determining indicator since the values of other indicators were observed to be almost equal. Thus Equation 22 was introduced to be the most appropriate equation for the city with a very small $t$-statistics value.

Table 4 indicates the monthly average daily diffuse solar radiation values which were calculated by using Equation 22. Since the measured data is unavailable, these values can be used in further studies to calculate the monthly average daily total solar radiation, optimum tilt angles and many parameters related to the radiation received on the surface of PV modules. $+$

\section{Conclusions}

In this paper nine new diffuse solar radiation equations were developed for Antalya, Turkey. The predicted results of the selected current equations were used as measured diffuse solar radiation values since there was no available data. The performance of the equations were evaluated by statistical indicators $M B E, M A B E, M A P E, R M S E, R^{2}$ and $t$-statistics. In conclusion Equation 22 , the quadratic function of the clearness index and the sunshine fraction, was selected to be the most accurate equation.

\section{References}

[1] World Energy Council Turkish National Committee; Energy Report 2013. 2014.

[2] Evrendilek F, Ertekin C. Assessing the potential of renewable energy sources in Turkey. Renewable Energy 2003; 28:2303-15

[3] http://www.yegm.gov.tr 
[4] Aksoy Tırmıkçı C, Yavuz C. Determining optimum tilt angles of solar surfaces in Sakarya, Turkey, Theor Appl Climatol 2018;133:15-22

[5] Page JK. The estimation of monthly mean values of daily total short wave radiation on vertical and inclined surface from sunshine records for latitudes 40N-40S.In: Proceedings of UN Conference on New Sources of Energy 1961;4(598):378-90

[6] Aras H, Balli O, Hepbasli A. Estimating the horizontal diffuse solar radiation over the Central Anatolia Region of Turkey. Energy Convers Manage 2006;47:2240-49.

[7] Tarhan S, Sari A. Model selection for global and diffuse radiation over the Central Black Sea (CBS) region of Turkey. Energy Convers Manage 2005;46(4):605-13.

[8] Iqbal M. Correlation of average diffuse and beam radiation with hours of bright sunshine. Solar Energy 1979;23(2):169-73.

[9] Barbaro S, Cannata G, Coppolino S, Leone C, Sinagra E. Diffuse solar radiation statistics for Italy. Solar Energy 1981;26:429-35.

[10] Erbs DG, Klein SA, Duffie JA. Estimation of the diffuse radiation fraction for hourly, daily and monthly average global radiation. Solar Energy 1982;28: 293-302.

[11] Jiang Y. Estimation of monthly mean daily diffuse radiation in China. Applied Energy 2009;86:1458-64.

[12] Khorasanizadeh H, Mohammadi K, Mostafaeipour A. Establishing a diffuse solar radiation model for determining the optimum tilt angle of solar surfaces in Tabass, Iran. Energy Conversion and Management 2014;78:805-14.

[13] Iqbal M. An introduction to solar radiation. New York, USA: Academic Press, 1983.

[14] Duffie JA, Beckman WA. Solar engineering of thermal processes 3rd ed. New York: John Wiley \& Son, 2006.

[15] Cooper PI. The absorption of solar radiation in solar stills. Solar Energy 1969; 12:333-46. 